\title{
Dynamical Analysis of Carrier-Track Contact Model in a Braiding Machine
}

\author{
Yujing ZHANG, Zhuo MENG*, Chengjie DU, Yize SUN
}

\begin{abstract}
As vibrations caused by the coupling of carriers and tracks could affect the performance of braiding machines a lot, it is necessary to establish the carrier-track contact model and investigate its dynamic characteristics. Therefore, a dynamic model of carrier-track contact model has been developed. Based on the Hertz's law and Newton's law, the dynamical equations of carriers were established. The influence of contact related parameters to the carriers' dynamic characteristics were discussed. Besides, a comparison of contact parameters with different contact models was presented. The results show that although carriers keep a low contact speed, collisions still exist during carriers transferring between tracks. To avoid/decrease collisions and shocks, some methods were proposed, e.g. controlling the angular velocity of horn gears variable, changing the contact surface to have a higher coefficient of restitution and reducing the vibration of frame and tracks, which could be helpful to the design of braiding machines.
\end{abstract}

Keywords: braiding machine; carrier-track; contact model; dynamical analysis; track vibration

\section{INTRODUCTION}

Maypole braiding is a continuous braiding technology, which could produce composite preforms with a quite high productivity. These preforms are widely used in various fields, having higher-performance of mechanical properties than the traditional ones.

Since braiding has broad application prospects, many studies have been reported. Books written by Yordan Kyosev systematically introduced the braiding technique. In the books, several types of carriers have been introduced, as well as the rule of their movements $[1,2]$. Lepperhoff and Goseberg et al. also studied the relationship between carrier arrangement and pattern type $[3,4]$. A well-known software TexMind Configurator explored by Kyosev could emulate the carrier occupation [5]. Ma et al. focused on the passive tensioning system of carriers, and established a mathematical model to illustrate how the tensioning system works [6]. Other studies mostly focused on the braiding process related parameters, e.g. braiding angle, cover ratio, braid patterns [7-9].

Carrier, as a most important part, could greatly influence the braiding. In practical engineering, the braiding productivity depends on the performance of carriers to some extent. If the braid speed is up, carriers vibrate seriously. Vibrations of carriers could easily result in the fiber knot or fiber fuzz, forcing the machine shut down.

However, there are few articles, which focused on the dynamic characteristic of carriers. Diagrams of a carrier are drawn in Fig. 1 taken on the spot. In a braiding machine, carriers are mounted on the slot of horn gears, having two guide pads as its feet. By the push forces from the horn gears, carriers are moving forward along the tracks/tracks. There are two sliding pairs in the system. One is the guide pad and the track, while the other one is the carrier and the horn gear. It is well known that when the surfaces of two parts are placed in contact and allowed to slide, friction, impact and vibration would occur during the motion.

Some articles on the contact and friction have been reported for decades. Articles written by Johnson and Flores systematically introduced the contact mechanics and the evolution of the Hertz contact theory $[10,11]$. Researchers have studied the contact mechanism from many aspects. Pournaras et al. proposed a method for detecting contact among the components of a system of solid bodies [12].

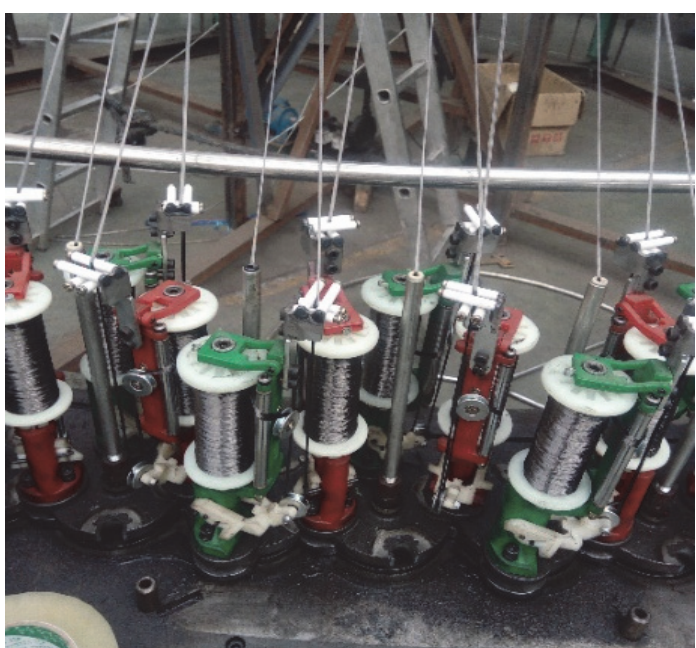

(a) Scene picture

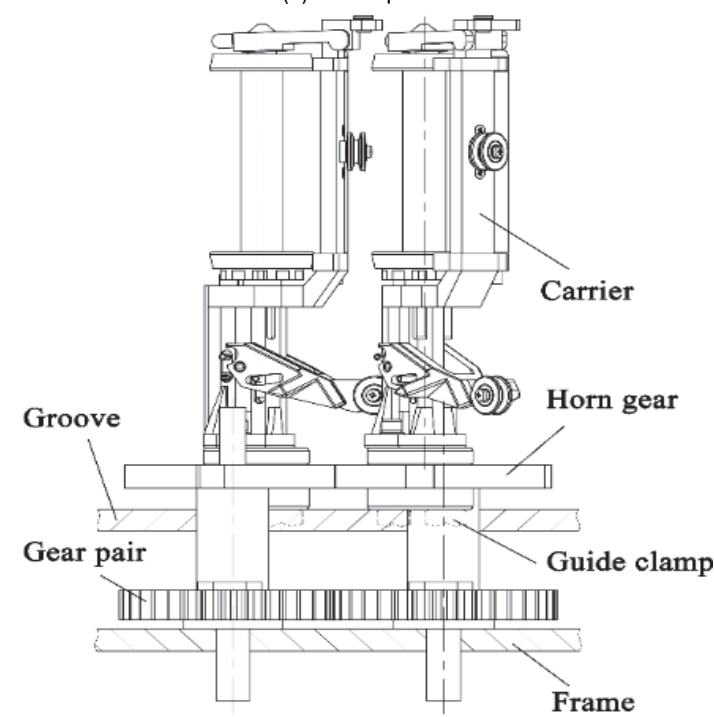

(b) Schematic diagram

Figure 1 Diagrams of carrier-track contact model

Zobova presented different models of distributed dry friction theories [13]. Gholami et al. proposed a mathematical formulation of regularized friction to solve 
multi-body contact problems [14]. Varedi et al. introduced an optimization method to alleviate the undesirable effects of joint clearance in a planar slider-crank mechanism [15]. Kacianauskas et al. investigated the propagation of force and the impact velocity in a chain of contacting particles [16]. Serweta et al. investigated the influence of the frequency of excitation force on the system's behavior by Lyapunov exponents [17]. Zdancevičiusa et al. developed a general damping model of coefficient of restitution, which is more accurate than the existing damping models [18].

In this paper, a mathematical model of carrier-track contact is presented, which is based on Hertz's law and Newton's law. Then the dynamic characteristic of this model will be investigated under different parameters. By the analysis, an optimized model and an effective measure of vibration reduction will be discussed and verified, which is helpful for the practical engineering.

\section{DYNAMICAL EQUATIONS OF CARRIER-TRACK CONTACT MODEL}

There are three objects in the following dynamic analysis, the carrier, the horn gear and the track. During the braiding process, carriers are always moving along the track under the push force from horn gears, changing their track from one horn gear to another. They transport yarns under as constant a tension as possible.

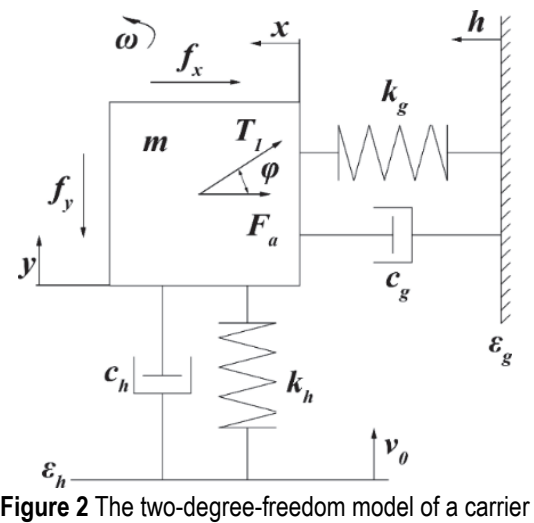

Assume the angular speed of horn gears as $\omega$, the turning radius of carrier as $r_{\mathrm{c}}$; the tangent speed of carriers as $v_{0}$, and the tension of fibers as $T_{1}$ in horizontal direction, $T_{2}$ in vertical direction. In vertical direction, horn gears and carriers are close to each other, and there is no clearance between them; in the radial direction of horn gears, carriers could move with a displacement of $x$. In order to smoothly change tracks between horn gears, there is a clearance $\varepsilon_{\mathrm{h}}$ between horn gears and carriers in the moving direction, which will induce carriers having a displacement of $y$. Similarly, to move smoothly along the track, there is also a significant clearance $\varepsilon_{\mathrm{g}}$ between the guide pads and the track. According to the generalized Newton's second law of motion, the governing equations of a carrier are derived as:

$$
\begin{aligned}
& m \ddot{x}-F_{\mathrm{g}}(x, \dot{x})+f_{x}(\dot{x})+T_{1} \cos \varphi+F_{\mathrm{a}}= \\
& =k_{\mathrm{g}} h(y, t)+c_{\mathrm{g}} \dot{h}(y, t)
\end{aligned}
$$

$$
m \ddot{y}-F_{\mathrm{h}}(y, \dot{y})+f_{y}(x, \dot{y})-T_{1} \sin \varphi=k_{\mathrm{h}} v_{0} t+c_{\mathrm{h}} v_{0}
$$

where, $m$ is the mass of carrier; $t$ is the time; $\varphi$ is the angle of $T_{1}$ and $x$ direction; $F_{\mathrm{a}}=m r_{\mathrm{c}} \omega^{2}$ is the inertia force; $F_{\mathrm{g}}(x, \dot{x})$ and $F_{\mathrm{h}}(y, \dot{y})$ are contact forces; $f_{x}(\dot{x})$ and $f_{y}(x, \dot{y})$ are frictions; $h=h_{\mathrm{a}} \cos \omega_{\mathrm{h}} t$ is the displacement due to the vibration transmitted from the frame and exciting motor to the track, $h_{\mathrm{a}}$ is the amplitude of the vibration, $\omega_{\mathrm{h}}$ is the excitation frequency; $k_{\mathrm{g}}, c_{\mathrm{g}}, k_{\mathrm{h}}, c_{\mathrm{h}}$ are time-varying contact stiffness coefficient and damping coefficient determined by the guide pads and the track, the carrier and the horn gear, respectively.

The above contact forces and the relevant parameters could be derived by the different contact force models as follows.

If we consider the contact as a pure elastic process, then the contact forces are:

$$
F_{\mathrm{g}}(x, \dot{x})=k_{\mathrm{g}} p_{\mathrm{g}}(x) ; F_{\mathrm{h}}(y, \dot{y})=k_{\mathrm{h}} p_{\mathrm{h}}(y)
$$

where $p_{\mathrm{g}}(x)=\left\{\begin{array}{ll}(-x)^{n}, & x<0 \\ 0, & 0<x<\varepsilon_{\mathrm{g}}\end{array} ; p_{\mathrm{h}}(y)=\left\{\begin{array}{ll}(-y)^{n}, & y<0 \\ 0, & 0<y<\varepsilon_{\mathrm{h}} \\ \left(x-\varepsilon_{\mathrm{g}}\right)^{n}, & \varepsilon_{\mathrm{g}}<x\end{array}\right.\right.$,

$n$ is the nonlinear power exponent determined by the materials and geometric properties of the contact manner, for Hertz's law $n=3 / 2$ and for a more accurate model proposed by Brändlein $n=1.08$.

With the Hertz's law, the contact stiffness parameters are:

$k_{\mathrm{g}}=\frac{4}{3} E_{12} R_{12}^{1 / 2} ; k_{\mathrm{h}}=\frac{4}{3} E_{34} R_{34}^{1 / 2}$

where $E_{12}=\left(\frac{1-v_{1}^{2}}{E_{1}}+\frac{1-v_{2}^{2}}{E_{2}}\right)^{-1} ; E_{34}=\left(\frac{1-v_{3}^{2}}{E_{3}}+\frac{1-v_{4}^{2}}{E_{4}}\right)^{-1}$; $R_{12}=\left(\frac{1}{R_{1}}-\frac{1}{R_{2}}\right)^{-1} ; \quad R_{34}=\left(\frac{1}{R_{3}}-\frac{1}{R_{4}}\right)^{-1} ; R_{i}, v_{i}$ and $E_{i}$ denote the radius of contact area, the Poisson's ratio and the Young's modulus of guide pad, track, carrier and horn gear, respectively $(i=1,2,3,4)$.

However, if we consider the contact as an energy dissipation process, the restitution phases of contact could be observed. Several dissipative contact force models have been proposed.

For the Hunt and Crossley contact force model [19], the expressions of contact forces are:

$$
\begin{aligned}
& F_{\mathrm{g}}(x, \dot{x})=k_{\mathrm{g}} p_{\mathrm{g}}(x)\left(1+\frac{3\left(1-c_{\mathrm{r} 1}\right) \dot{x}}{2 \dot{x}^{(-)}}\right) \\
& F_{\mathrm{h}}(y, \dot{y})=k_{\mathrm{h}} p_{\mathrm{h}}(y)\left(1+\frac{3\left(1-c_{\mathrm{r} 2}\right) \dot{y}}{2 \dot{y}^{(-)}}\right)
\end{aligned}
$$


where $c_{\mathrm{r} 1}, c_{\mathrm{r} 2}$ are the coefficient of restitution; $\dot{x}^{(-)}, \dot{y}^{(-)}$ are the initial impact velocities.

For the Herbert and McWhannell contact force model [20], the contact forces are:

$F_{\mathrm{g}}(x, \dot{x})=k_{\mathrm{g}} p_{\mathrm{g}}(x)\left(1+\frac{6\left(1-c_{\mathrm{r} 1}\right) \dot{x}}{\left(\left(2 c_{\mathrm{r} 1}-1\right)^{2}+3\right) \dot{x}^{(-)}}\right)$

$F_{\mathrm{h}}(y, \dot{y})=k_{\mathrm{h}} p_{\mathrm{h}}(y)\left(1+\frac{6\left(1-c_{\mathrm{r} 2}\right) \dot{y}}{\left(\left(2 c_{\mathrm{r} 2}-1\right)^{2}+3\right) \dot{y}^{(-)}}\right)$

For the Lee and Wang contact force model [21], the expressions of contact forces are:

$$
\begin{aligned}
& F_{\mathrm{g}}(x, \dot{x})=k_{\mathrm{g}} p_{\mathrm{g}}(x)\left(1+\frac{3\left(1-c_{\mathrm{r} 1}\right) \dot{x}}{4 \dot{x}^{(-)}}\right) \\
& F_{\mathrm{h}}(y, \dot{y})=k_{\mathrm{h}} p_{\mathrm{h}}(y)\left(1+\frac{3\left(1-c_{\mathrm{r} 2}\right) \dot{y}}{4 \dot{y}^{(-)}}\right)
\end{aligned}
$$

For the Lankarani and Nikravesh contact force model [22], the expressions of contact forces are:

$$
\begin{aligned}
& F_{\mathrm{g}}(x, \dot{x})=k_{\mathrm{g}} p_{\mathrm{g}}(x)\left(1+\frac{3\left(1-c_{\mathrm{r} 1}^{2}\right) \dot{x}}{4 \dot{x}^{(-)}}\right) \\
& F_{\mathrm{h}}(y, \dot{y})=k_{\mathrm{h}} p_{\mathrm{h}}(y)\left(1+\frac{3\left(1-c_{\mathrm{r} 2}^{2}\right) \dot{y}}{4 \dot{y}^{(-)}}\right)
\end{aligned}
$$

For the Gonthier contact force model [23], the expressions of contact forces are:

$$
\begin{aligned}
& F_{\mathrm{g}}(x, \dot{x})=k_{\mathrm{g}} p_{\mathrm{g}}(x)\left(1+\frac{\left(1-c_{\mathrm{r} 1}^{2}\right) \dot{x}}{c_{\mathrm{r} 1} \dot{x}^{(-)}}\right) \\
& F_{\mathrm{h}}(y, \dot{y})=k_{\mathrm{h}} p_{\mathrm{h}}(y)\left(1+\frac{\left(1-c_{\mathrm{r} 2}^{2}\right) \dot{y}}{c_{\mathrm{r} 2} \dot{y}^{(-)}}\right)
\end{aligned}
$$

For the Zhiying and Qishao contact force model [24], the expressions of contact forces are:

$$
\begin{aligned}
& F_{\mathrm{g}}(x, \dot{x})=k_{\mathrm{g}} p_{\mathrm{g}}(x)\left(1+\frac{3\left(1-c_{\mathrm{r} 1}^{2}\right) \mathrm{e}^{2\left(1-c_{\mathrm{r} 1}\right)} \dot{x}}{4 \dot{x}^{(-)}}\right) \\
& F_{\mathrm{h}}(y, \dot{y})=k_{\mathrm{h}} p_{\mathrm{h}}(y)\left(1+\frac{3\left(1-c_{\mathrm{r} 2}^{2}\right) \mathrm{e}^{2\left(1-c_{\mathrm{r} 2}\right)} \dot{y}}{4 \dot{y}^{(-)}}\right)
\end{aligned}
$$

For the Flores contact force model [25], the expressions of contact forces are

$$
\begin{aligned}
& F_{\mathrm{g}}(x, \dot{x})=k_{\mathrm{g}} p_{\mathrm{g}}(x)\left(1+\frac{8\left(1-c_{\mathrm{r} 1}\right) \dot{x}}{5 c_{\mathrm{r} 1} \dot{x}^{(-)}}\right) \\
& F_{\mathrm{h}}(y, \dot{y})=k_{\mathrm{h}} p_{\mathrm{h}}(y)\left(1+\frac{8\left(1-c_{\mathrm{r} 2}\right) \dot{y}}{5 c_{\mathrm{r} 1} \dot{y}^{(-)}}\right)
\end{aligned}
$$

In Eq. (5) to Eq. (13), the parameters $k_{\mathrm{g}}, k_{\mathrm{h}}, p_{\mathrm{g}}(x)$ and $p_{\mathrm{h}}(x)$ are the same as in Eq. (4), and $c_{\mathrm{g}}, c_{\mathrm{h}}$ could be easily deduced in different models.

On the other hand, the frictions in Eq. (1) and Eq. (2) are given by:

$$
\begin{aligned}
& f_{x}(\dot{x})=\frac{2}{\pi} \mu_{1}\left|m g-T_{2}\right| \arctan (\dot{x} / \hat{\dot{x}}) \\
& f_{y}(x, \dot{y})=\frac{2}{\pi} \mu_{2} F_{\mathrm{g}}(x, \dot{x}) \arctan (\dot{y} / \hat{\dot{y}})
\end{aligned}
$$

where $\mu_{1}$ is the coefficient of friction between the carrier and the horn gear; $\mu_{2}$ is the coefficient of friction between the guide pad and the track; $\hat{\dot{x}}, \hat{\dot{y}}$ are very small velocities compared with $\dot{x}$ and $\dot{y}$.

\section{DYNAMIC CHARACTERISTICS OF THE MODEL WITH DIFFERENT CONTACT PARAMETERS}

For a carrier, it has to change its orbit between different horn gears all the time, while the guide padal so has to change the direction of movement along the track. To avoid collision and keep the movement smoothly, the clearance $\varepsilon_{\mathrm{g}}$ of the guide pad and the track has to be big enough. On the other hand, compared with $\varepsilon_{\mathrm{g}}$, the clearance $\varepsilon_{\mathrm{h}}$ of the carrier and the horn gear is a smaller value, since the transmission is easier for carriers from one horn gear to another. Therefore, the shock is mainly caused by the collision between the guide pad and the track. The carrier dynamic characteristic in $x$ direction would be analyzed and discussed as follows.

According to the practical engineering, the values of parameters in the model are assigned as: $m=1.2 \mathrm{~kg}, \mu_{1}=$ $\mu_{2}=0.1, E_{i}=2 \mathrm{GPa}, v_{i}=0.3(i=1,2,3,4), R_{1}=20 \mathrm{~mm}$, $R_{2}=65 \mathrm{~mm}, R_{3}=10 \mathrm{~mm}, T_{1}=5 \mathrm{~N}, T_{2}=3 \mathrm{~N}, c_{\mathrm{r} 1}=c_{\mathrm{r} 2}=5 / 9$, $r_{\mathrm{c}}=65 \mathrm{~mm}, \omega=4 \pi, \varphi=\pi / 6, \varepsilon_{\mathrm{g}}=3 \mathrm{~mm}, \varepsilon_{\mathrm{h}}=0.1 \mathrm{~mm}, h_{\mathrm{a}}=$ $0.1 \mathrm{~mm}, \omega_{\mathrm{h}}=120 \pi$. Besides, the initial conditions are defined as: $x_{0}=0, y_{0}=0, \dot{y}_{0}=0$. With the Hunt and Crossley contact force model, the results of the dynamic characteristics are shown in the following diagrams. For convenience, assign $F_{\mathrm{kg}}, F_{\mathrm{cg}}$ and $\delta_{x}$ as the time-varying stiffness-related component force, damping-related component force and contact depth, respectively.

\subsection{Without Track Vibration during Carriers Moving in One Horn Gear}

If the vibration of track is ignored, the displacement $x$ mainly depends on the initial conditions. Fig. 3 shows the curve of $x$ with the initial conditions of $\dot{x}_{0}=0.5 \mathrm{~m} / \mathrm{s}$, and the corresponding vibration curves of track are also depicted for reference. While the initial impact speed $\dot{x}_{0}$ is 
small, collision will not occur. With the value of $\dot{x}_{0}$ increasing up to $0.5 \mathrm{~m} / \mathrm{s}$, collision could be observed.

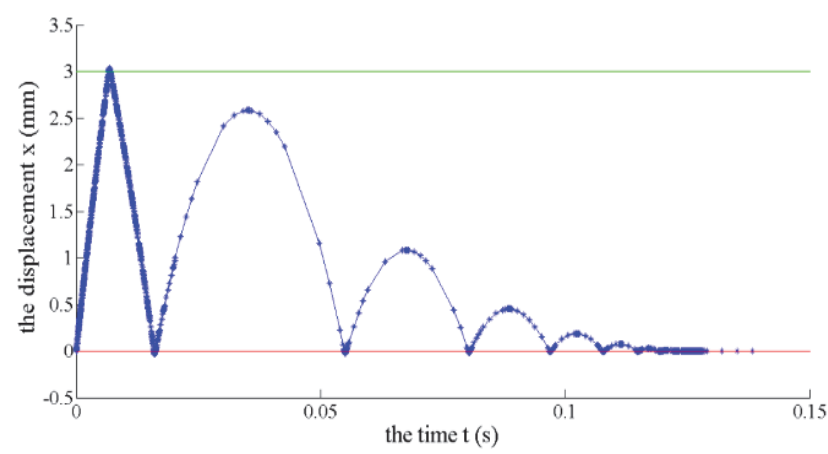

Figure 3 Diagram of the displacement $x$ without the track vibration

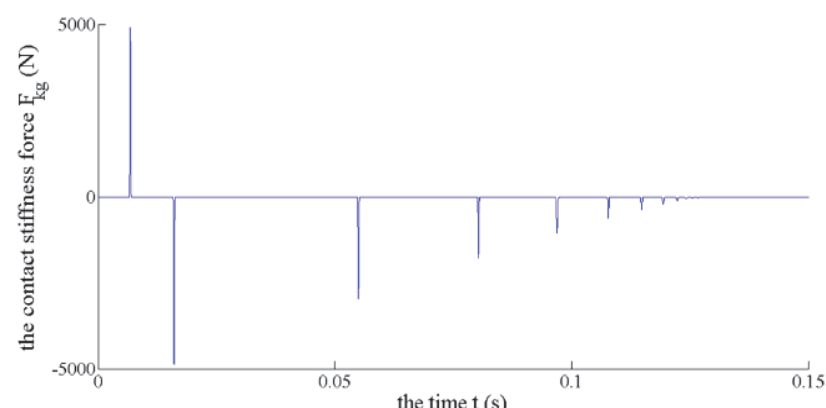

Figure 4 Diagram of the stiffness-related component force $F_{\mathrm{kg}}$ without the track vibration

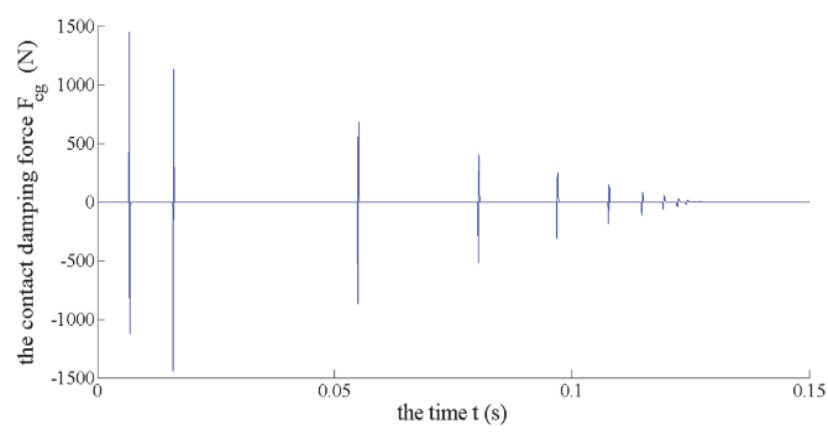

Figure 5 Diagram of the damping-related component force $F_{\mathrm{cg}}$ without the track vibration

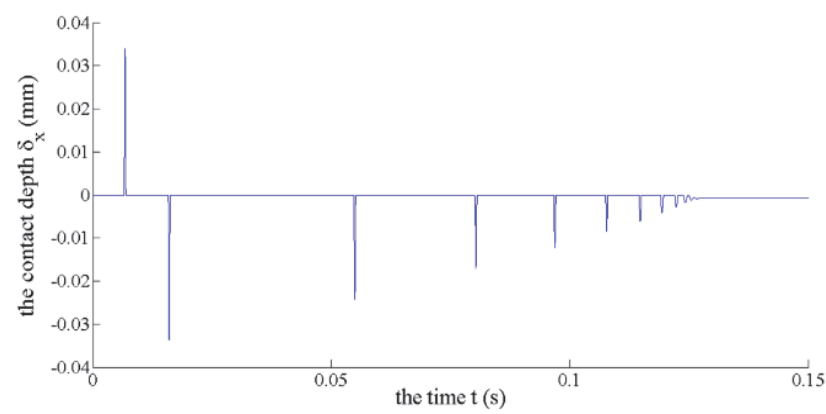

Figure 6 Diagram of the contact depth $\delta_{x}$ without the track vibration

The value of the stiffness-related component force $F_{\mathrm{kg}}$ (Fig. 4) is in the range of $(-4864.4 \mathrm{~N}, 4921.4 \mathrm{~N})$, while the value of the damping-related component force $F_{\mathrm{cg}}$ (Fig. 5) is in the range of $(-1441.2 \mathrm{~N}, 1448.8 \mathrm{~N})$. During the contact, the contact depth $\delta_{x}$ (Fig. 6) is varying in the range of $\left(-3.37 \times 10^{-2} \mathrm{~mm}, 3.39 \times 10^{-2} \mathrm{~mm}\right)$ initially, and is maintained at the value $-7.53 \times 10^{-4} \mathrm{~mm}$ later. Here, the positive and negative value denotes the bilateral track surface contact.

\subsection{Without Track Vibration during Carriers Transferring Between Horn Gears}

As discussed above, a small initial impact speed might not induce collision while carriers keep their movement in one horn gear. However, collision could occur during carriers transferring between different horn gears. Suppose the vibration of track is ignored, and carriers have achieved a stable state as shown in Fig. 3. Assign $\dot{x}_{0}=2 \mathrm{~mm} / \mathrm{s}$, which is a reasonable contact speed for carriers. The transfer will induce the initial condition $\dot{x}_{0}=0$ changing into $x_{0}=3 \mathrm{~mm}$. The diagram of the displacement $x$ is shown in Fig. 7.

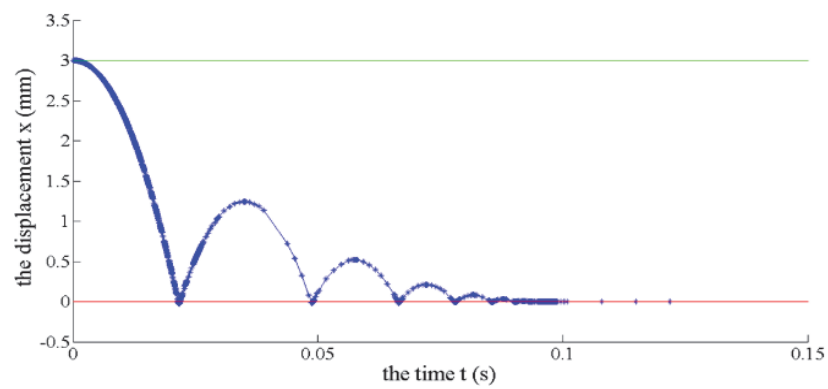

Figure 7 Diagram of the displacement $x$ during carriers' track transfer

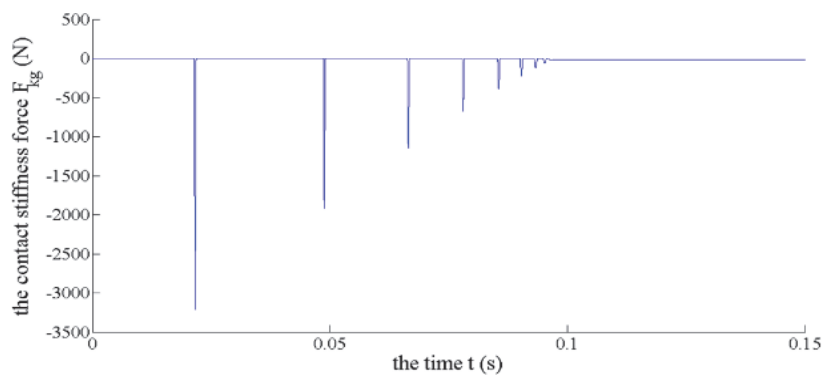

Figure 8 Diagram of the stiffness-related component force $F_{\mathrm{kg}}$ during carriers' track transfer

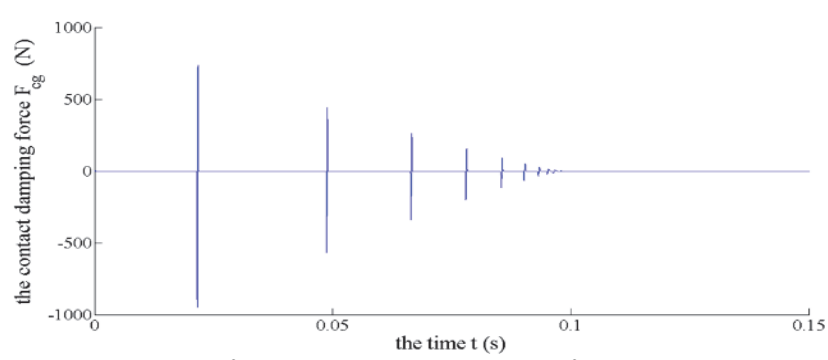

Figure 9 Diagram of the damping-related component force $F_{\text {cg }}$ during carriers' track transfer

Although the initial contact speed is very small, collisions also could be observed, which is similar to the situation of a big contact speed in Fig. 3 to Fig. 6. The value of the stiffness-related component force $F_{\mathrm{kg}}$ (Fig. 8) is in the range of $(-3210.6 \mathrm{~N}, 1.2 \mathrm{~N})$, while the value of the damping-related component force $F_{\text {cg }}$ (Fig. 9) is in the range of $(-948.1 \mathrm{~N}, 736.3 \mathrm{~N})$. During the contact, the contact depth $\delta_{x}$ (Fig. 10) is varying in the range of $\left(-2.55 \times 10^{-2} \mathrm{~mm}, 1.32 \times 10^{-4} \mathrm{~mm}\right)$ initially, and is maintained at the value $-7.47 \times 10^{-4} \mathrm{~mm}$ later. 


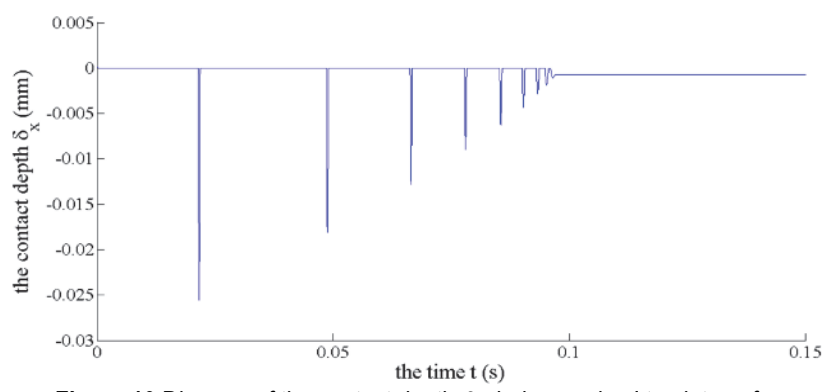

Figure 10 Diagram of the contact depth $\delta_{x}$ during carriers' track transfer

\subsection{With Small Track Vibration}

Actually, once the braiding process starts, the vibration of tracks always exists. If the vibration of tracks is considered, serious impact could be observed in Fig. 11. Here, assign $\dot{x}_{0}=2 \mathrm{~mm} / \mathrm{s}$ and $h_{\mathrm{a}}=0.12 \mathrm{~mm}$. Carriers and tracks collide with each other not only on the inner surface but also on the outer surface. After several times, carriers keep a small vibration due to the vibration of the track. The value of the stiffness-related component force $F_{\mathrm{kg}}$ (Fig. 12) is in the range of $(-32737 \mathrm{~N}, 26470 \mathrm{~N})$ initially, and $(-1511.5 \mathrm{~N}, 0 \mathrm{~N})$ later, while the value of the dampingrelated component force $F_{\text {cg }}$ (Fig. 13) is in the range of $(-6407.6 \mathrm{~N}, 7650.6 \mathrm{~N})$ initially, and $(-375.8 \mathrm{~N}, 717.4 \mathrm{~N})$ later. During the contact, the contact depth $\delta_{x}$ (Fig. 14) is in the range of $\left(-1.20 \times 10^{-1} \mathrm{~mm}, 1.04 \times 10^{-1} \mathrm{~mm}\right)$ initially, and $\left(-1.61 \times 10^{-2} \mathrm{~mm}, 0 \mathrm{~mm}\right)$ later.

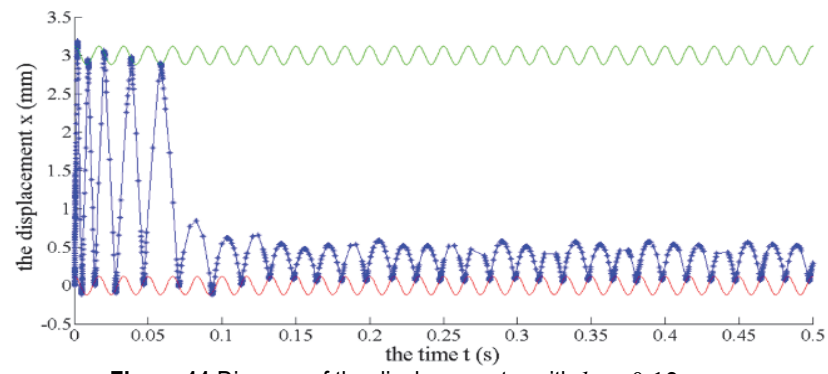

Figure 11 Diagram of the displacement $x$ with $h_{\mathrm{a}}=0.12 \mathrm{~mm}$

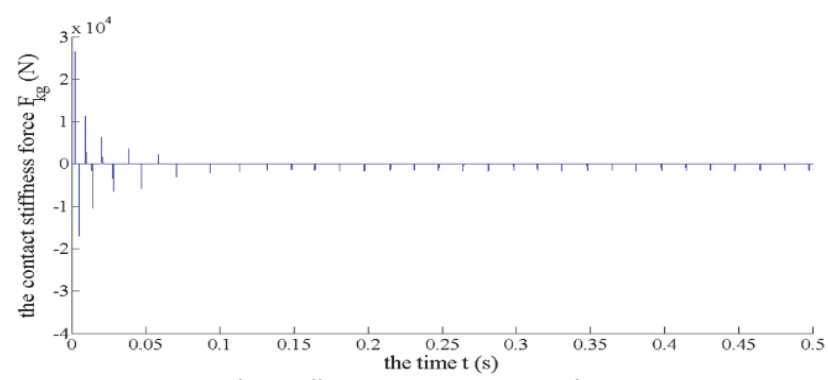

Figure 12 Diagram of the stiffness-related component force $F_{\mathrm{kg}}$ with $h_{\mathrm{a}}=0.12$ $\mathrm{mm}$

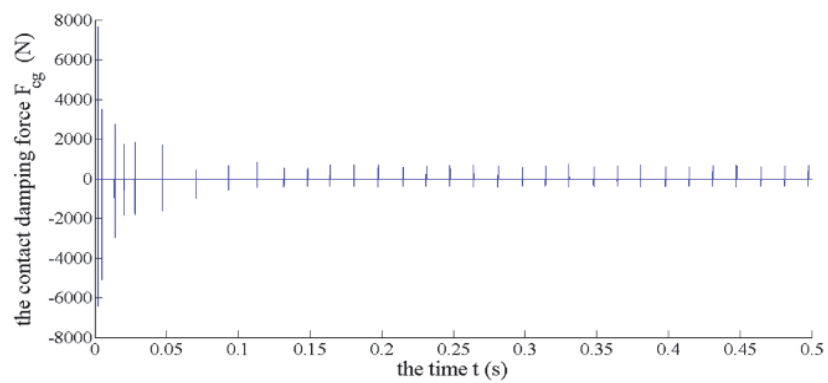

Figure 13 Diagram of the damping-related component force $F_{\text {cg }}$ with $h_{\mathrm{a}}=0.12$

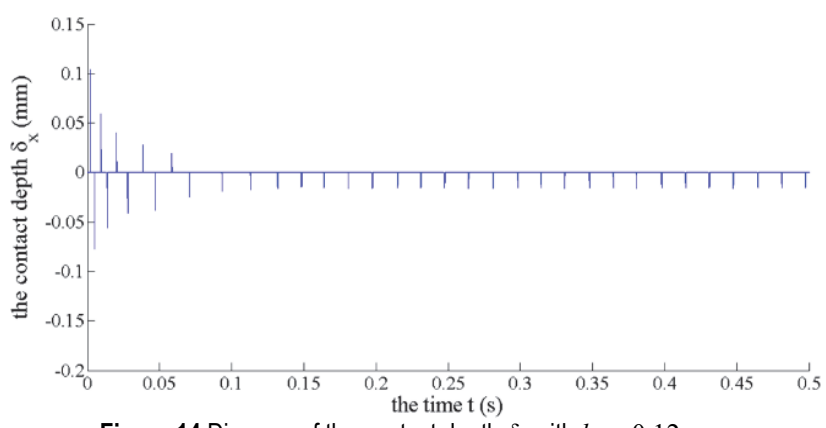

Figure 14 Diagram of the contact depth $\delta_{x}$ with $h_{\mathrm{a}}=0.12 \mathrm{~mm}$

\subsection{With Large Track Vibration}

While the frame and exciting motor keep running at a high speed, the vibration of tracks would become serious. In Fig. 15, the frequency of collision is very high initially, and later is reduced to a steady value, which depends on the vibration frequency of the frame and exciting motor. Corresponding contact parameters are shown in Fig. 16 to Fig. 18. The value of the stiffness-related component force $F_{\mathrm{kg}}$ (Fig. 16) is in the range of $(-199229 \mathrm{~N}, 161983 \mathrm{~N})$ initially, and $(-8416.5 \mathrm{~N}, 6481.4 \mathrm{~N})$ later, while the value of the damping-related component force $F_{\mathrm{cg}}$ (Fig. 17) is in the range of $(-37722 \mathrm{~N}, 47817 \mathrm{~N})$ initially, and $(-2968.1$ $\mathrm{N}, 3182.8 \mathrm{~N}$ ) later. During the contact, the contact depth $\delta_{x}$ (Fig. 18) is in the range of $(-0.400 \mathrm{~mm}, 0.348 \mathrm{~mm})$ initially, and $\left(-4.86 \times 10^{-2} \mathrm{~mm}, 4.07 \times 10^{-2} \mathrm{~mm}\right)$ later.

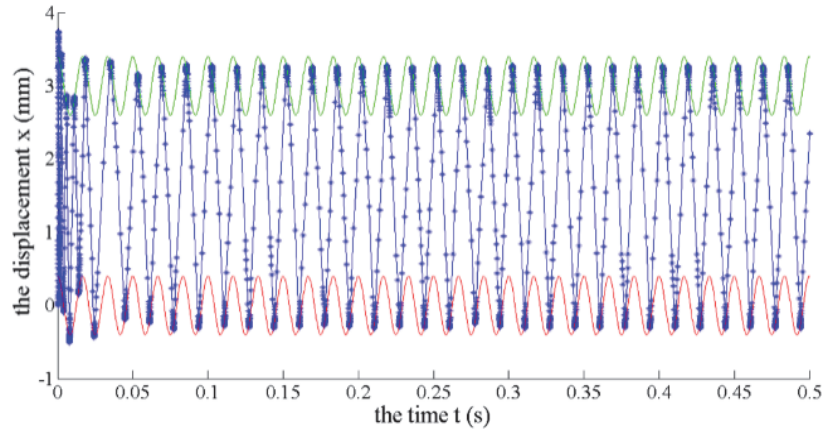

Figure 15 Diagram of the displacement $x$ with $h_{\mathrm{a}}=0.4 \mathrm{~mm}$

On the other hand, assume the amplitude of track vibration as $h_{\mathrm{a}}=0.12 \mathrm{~mm}$, which is the same as in Fig. 11, and increase the angular velocity of carriers $\omega$ up to $8 \pi$. The corresponding contact parameters could be derived as shown from Fig. 19 to Fig. 22. From Fig. 19, it can be seen that carriers and tracks collide with each other at the beginning, and soon they bond together, which is different from that in Fig. 11. The value of the stiffness-related component force $F_{\mathrm{kg}}$ (Fig. 20) is in the range of $(-6069 \mathrm{~N}$, $476934 \mathrm{~N})$ initially, and $(-408.29 \mathrm{~N},-24.1 \mathrm{~N})$ later, while the value of the damping-related component force $F_{\text {cg }}$ (Fig. $21)$ is in the range of $(-4241.4 \mathrm{~N}, 338954 \mathrm{~N})$ initially, and $(-19.3 \mathrm{~N}, 386.4 \mathrm{~N})$ later. During the contact, the contact depth $\delta_{x}$ (Fig. 22) is in the range of $\left(-1.20 \times 10^{-1} \mathrm{~mm}\right.$, $\left.1.01 \times 10^{-1} \mathrm{~mm}\right)$ initially, and $\left(-6.52 \times 10^{-3} \mathrm{~mm},-8.44 \times 10^{-4}\right.$ $\mathrm{mm}$ ) later. 


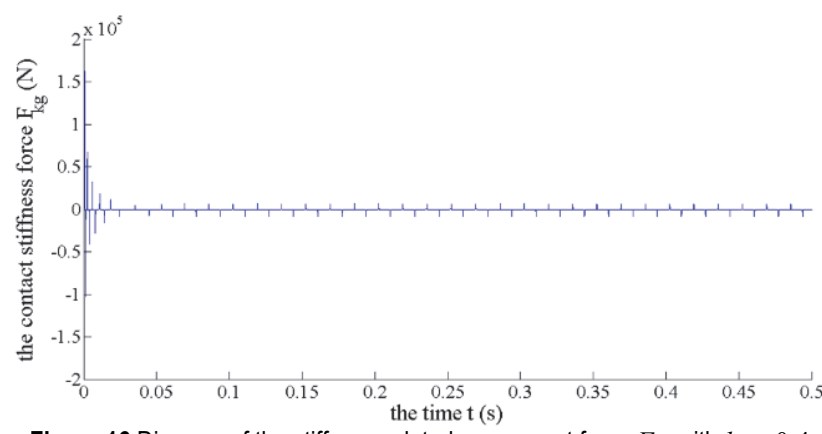

Figure 16 Diagram of the stiffness-related component force $F_{\mathrm{kg}}$ with $h_{\mathrm{a}}=0.4$ $\mathrm{mm}$

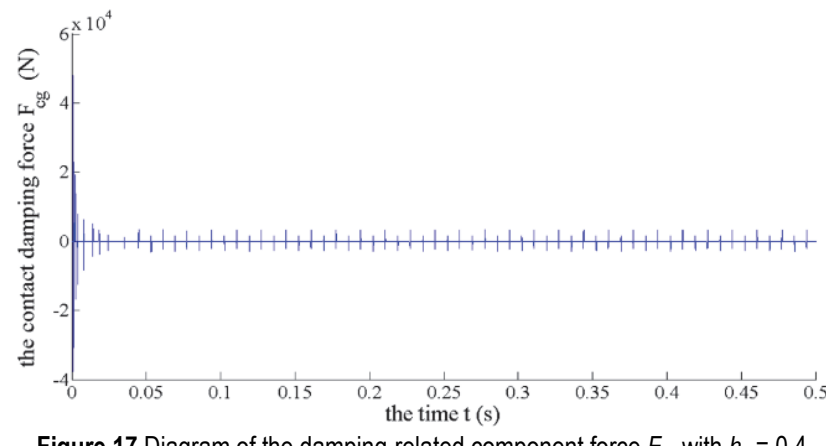

Figure 17 Diagram of the damping-related component force $F_{c g}$ with $h_{\mathrm{a}}=0.4$ $\mathrm{mm}$

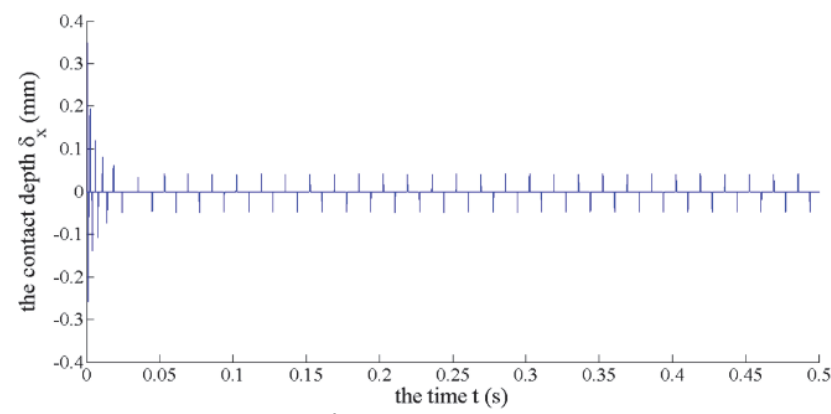

Figure 18 Diagram of the contact depth $\delta_{x}$ with $h_{\mathrm{a}}=0.4 \mathrm{~mm}$

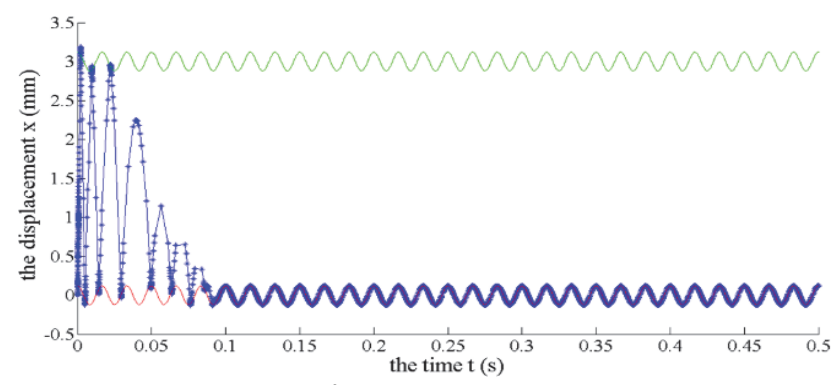

Figure 19 Diagram of the displacement $x$ while $\omega$ is up to $8 \pi$

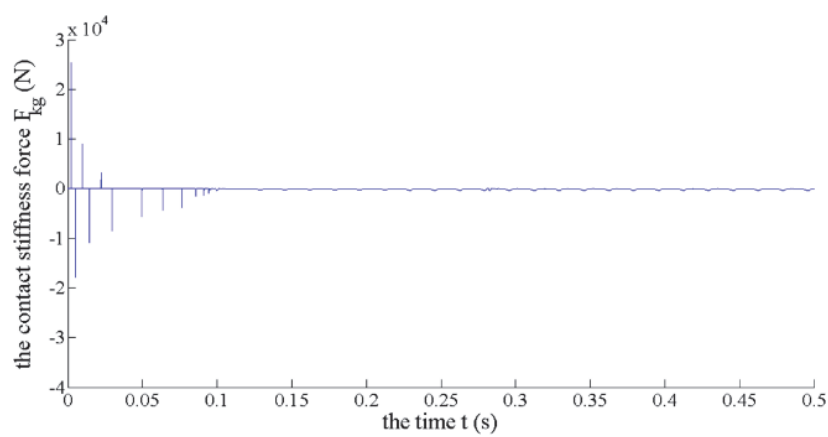

Figure 20 Diagram of the stiffness-related component force $F_{\mathrm{kg}}$ while $\omega$ is up to $8 \pi$

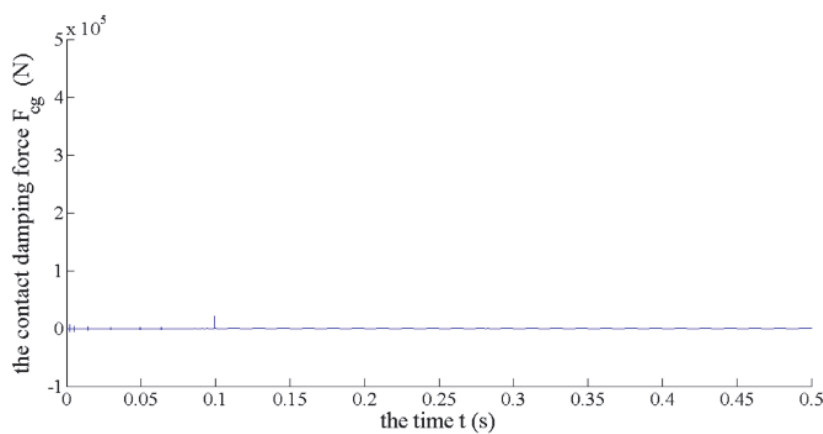

Figure 21 Diagram of the damping-related component force $F_{\mathrm{cg}}$ while $\omega$ is up to $8 \pi$

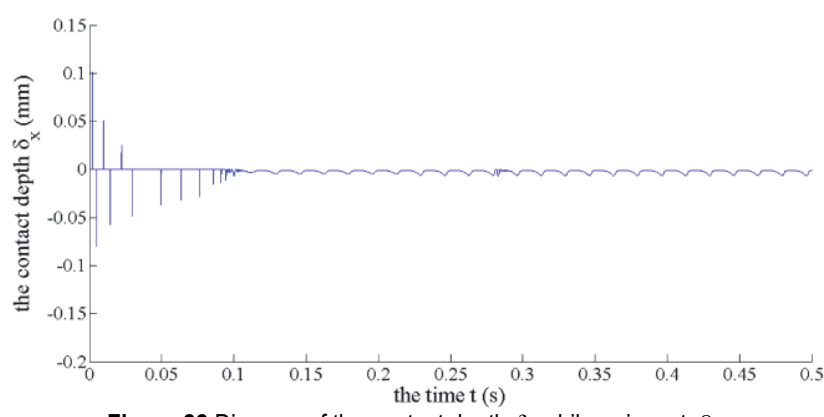

Figure 22 Diagram of the contact depth $\delta_{x}$ while $\omega$ is up to $8 \pi$

\subsection{Comparison of Different Contact Models}

To compare the influence of different contact models to contact parameters, Tab. 1 is drawn as follows. Here, the initial conditions are the same as in Fig. 3 to Fig. 6. The results of the Hertz's model and Brändlein's model are obviously smaller than other models, showing that a higher coefficient of restitution has a smaller contact force. Besides, no damping-related component force is considered in the two models. In other models, stiffnessrelated component force and damping-related component force are varying in a wide range. However, the total contact force and contact depth are about the same.

Table 1 Contact parameters in different contact models without track vibrations

\begin{tabular}{|c|c|c|c|c|}
\hline Model & Contact force / N & Stiffness-related component force / N & Damping-related component force / N & Contact depth $/ 10^{-2} \mathrm{~mm}$ \\
\hline Hertz [10] & $(-43,0)$ & $(-43,0)$ & 0 & $(-0.14,0)$ \\
\hline Brändlein [11] & $(-183,0)$ & $(-183,0)$ & 0 & $(-0.03,0)$ \\
\hline Crossley [19] & $(-5433,5532)$ & $(-4864,4921)$ & $(-1441,1449)$ & $(-3.37,3.39)$ \\
\hline McWhannell [20] & $(-5290,5517)$ & $(-4590,4817)$ & $(-1590,1656)$ & $(-3.24,3.34)$ \\
\hline Wang [21] & $(-6175,5643)$ & $(-5958,5464)$ & $(-901,825)$ & $(-3.85,3.64)$ \\
\hline Nikravesh [22] & $(-5704,5551)$ & $(-5300,5153)$ & $(-1223,1188)$ & $(-3.56,3.50)$ \\
\hline Gonthier [23] & $(-4497,5524)$ & $(-3976,4922)$ & $(-1215,1504)$ & $(-2.94,3.40)$ \\
\hline Zhiying [24] & $(-4851,5641)$ & $(-3722,4301)$ & $(-2015,2333)$ & $(-2.82,3.10)$ \\
\hline Flores [25] & $(-5364,5541)$ & $(-4719,4902)$ & $(-1484,1546)$ & $(-3.30,3.38)$ \\
\hline
\end{tabular}




\section{CONCLUSIONS}

A dynamic model of carrier-track contact model is presented. The influence of contact related parameters to the carriers' dynamic characteristics is investigated, e.g. the initial contact speed, the carriers' transfer between tracks, the vibration of frame and tracks and the angular velocity of horn gears.

The results show that although carriers keep a low contact speed, collisions still exist during carriers transferring between tracks. The vibration of frame and tracks could induce serious collisions, and if the amplitude of vibration continues to increase, the collision will occur on bilateral surfaces of tracks. Yet if the angular velocity of horn gears is big enough, the collision will disappear. On this occasion, the carriers and the tracks are indiscrete and are contacting with each other. The values of stiffnessrelated component force, damping-related component force and contact depth are existent but small.

Therefore, to avoid/decrease collisions and shocks, we could control the angular velocity of horn gears variable. Slow down the speed before carriers transferring the tracks, and increase the speed after carriers moving steadily. Other methods could be changing the contact surface to have a higher coefficient of restitution, reducing the vibration of frame and tracks, etc.

\section{Acknowledgments}

This project is supported by National Natural Science Foundation of China (Grant No. 51905088); Special Fund of Scientific and Technological Achievements Transformation in Jiangsu Province (Grant No. BA2018061); Fundamental Research Funds for the Central Universities (Grant No. 2232019D3-31).

\section{REFERENCES}

[1] Kyosev, Y. (2015). Braiding Technology for Textiles, Woodhead Publishing.

[2] Kyosev, Y. (2016). Advances in 3D Textiles, Woodhead Publishing.

[3] Goseberg, F., Brabender, K., \& Moeller, P. (1981). Textiltechnik Maschinengefl echte. Ausbildungsmittel Unterrichtshilfen. Frankfurt am Mai: Arbeitgeberkreis Gesamttextil.

[4] Lepperhoff, B. (1953). Die Flechterei. $3^{\text {rd }}$ edn., Eugen G. Leuze Verlag Saulgau/WTTBG.

[5] Kyosev, Y. (2014). Machine configurator for braided composite profiles with arbitrary cross sectio. ECCM, 16.

[6] Ma, G. L., Branscomb, D. J., \& Beale, D. G. (2012). Modeling of the tensioning system on a braiding machine carrier. Mech. Mach. Theory, 47, 46-61. https://doi.org/10.1016/j.mechmachtheory.2011.08.008

[7] Guyader, G., Gabor, A., \& Hamelin, P. (2013). Analysis of 2D and 3D circular braiding processes: Modeling the interaction between the process parameters and the pre-form architecture. Mech. Mach. Theory, 69, 90-104. https://doi.org/10.1016/j.mechmachtheory.2013.04.015

[8] Na, W. J., Ahn, H. C., Jeon, S. Y., Lee, J. S., Kang, H. M., \& $\mathrm{Yu}, \mathrm{W}$. R. (2014). Prediction of the braid pattern on arbitrary-shaped mandrels using the minimum path condition. Compos. Sci. Technol., 30-37. https://doi.org/10.1016/j.compscitech.2013.11.012

[9] Potluri, P., Rawal, A., Rivaldi, M., \& Porat, I. (2003). Geometrical modelling and control of a triaxial braiding machine for producing 3D preforms. Compos. Part A-Appl. S., 34, 481-492. https://doi.org/10.1016/S1359-835X(03)00061-7

[10] Johnson, K. L. (2003). Contact Mechanics, Cambridge University Press.

[11] Machado, M., Moreira, P., Flores, P., \& Lankarani, H. M. (2012). Compliant contact force models in multibody dynamics: Evolution of the Hertz contact theory. Mech Mach Theory, 53, 99-121. https://doi.org/10.1016/j.mechmachtheory.2012.02.010

[12] Pournaras, A., Karaoulanis, F., \& Natsiavas, S. (2017). Dynamics of mechanical systems involving impact and friction using an efficient contact detection algorithm. International Journal of Non-Linear Mechanics. https://doi.org/10.1016/j.jpnonlinmec.2016.08.007

[13] Zobova, A. A. (2016). A review of models of distributed dry friction, Pmm-J Appl Math Mec+, 80, 141-148. https://doi.org/10.1016/j.jappmathmech.2016.06.008

[14] Gholami, F., Nasri, M., Kovecses, J., \& Teichmann, M. (2016). A linear complementarity formulation for contact problems with regularized friction.Mech Mach Theory, 105, 568-582. https://doi.org/10.1016/j.mechmachtheory.2016.07.016

[15] Varedi, S. M., Daniali, H. M., Dardel, M., \& Fathi, A. (2015). Optimal dynamic design of a planar slider-crank mechanism with a joint clearance. Mech Mach Theory, 86, 191-200. https://doi.org/10.1016/j.mechmachtheory.2014.12.008

[16] Kacianauskas, R., Kruggel-Emden, H., Zdancevicius, E., \& Markauskas, D. (2016). Comparative evaluation of normal viscoelastic contact force models in low velocity impact situations. Advanced Powder Technology, 27, 1367-1379. https://doi.org/10.1016/j.apt.2016.04.031

[17] Serweta, W., Okolewski, A., Blazejczyk-Okolewska, B., Czolczynski, K., \& Kapitaniak, T. (2014). Lyapunov exponents of impact oscillators with Hertz's and Newton's contact models. International Journal of Mechanical Sciences, 89, 194-206. https://doi.org/10.1016/j.jimecsci.2014.09.007

[18] Zdancevičiusa, E., Kačianauskasa, R., \& Zabulionisa, D. (2017). Improvement of Viscoelastic Damping for the Hertz Contact of Particles due to impact velocity. Procedia Engineering, 172, 1286-1290. https://doi.org/10.1016/j.proeng.2017.02.156

[19] H. K. H. \& C. F. R. E. (1975). Coefficient of restitution interpreted as damping in vibro-impact. Journal of Applied Mechanics, 42, 440-445. https://doi.org/10.1115/1.3423596

[20] H. R. \& M. D. (1977). Shape and frequency composition of pulses from an impact pair. Journal of Engineering for Industry, 99, 513-518. https://doi.org/10.1115/1.3439270

[21] L. T. W. \&W. A. C. (1983). On the Dynamics of Intermittent-motion Mechanisms, Part 1: Dynami model and response. ASME Journal of Mechanisms Transmissions and Automation in Design, 105, 534-540. https://doi.org/10.1115/1.3267392

[22] L. H. M. \& N. P. E. (1994). Continuous contact force models for impact analysis in multibody systems.Nonlinear Dynamics, 5, 193-207.

[23] Gonthier, Y., McPhee, J., Lange, C. et al. (2004). A Regularized Contact Model with Asymmetric Damping and Dwell-Time Dependent Friction. Multibody System Dynamics, 11, 209-233. https://doi.org/10.1023/B:MUBO.0000029392.21648.bc

[24] Zhiying, Q. \& Qishao, L. (2006). Analysis of impact process based on restitution coefficient. Journal of Dynamics and Control, 4, 294-298.

[25] Flores, P. \& Ambrosio, J. (2010). On the contact detection for contact-impact analysis in multibody systems. Multibody System Dynamics, 24, 103-122. https://doi.org/10.1007/s11044-010-9209-8 


\section{Contact information:}

\section{Yujing ZHANG}

College of Mechanical Engineering,

Donghua University,

Shanghai, China

\section{Zhuo MENG}

(Corresponding author)

College of Mechanical Engineering,

Donghua University,

No. 2999, North Renming Road,

Songjiang District, Shanghai, China

E-mail: mz@dhu.edu.cn

\section{Chengjie DU}

College of Mechanical Engineering,

Donghua University,

Shanghai, China

\section{Yize SUN}

College of Mechanical Engineering,

Donghua University,

Shanghai, China 